University of Rhode Island

DigitalCommons@URI

$12-2013$

\title{
Do Tregitopes have the potential to impact the current treatment landscape of autoimmune diseases?
}

Anne S. De Groot

University of Rhode Island, annied@uri.edu

Follow this and additional works at: https://digitalcommons.uri.edu/immunology_facpubs

The University of Rhode Island Faculty have made this article openly available.

Please let us know how Open Access to this research benefits you.

This is a pre-publication author manuscript of the final, published article.

Terms of Use

This article is made available under the terms and conditions applicable towards Open Access Policy Articles, as set forth in our Terms of Use.

\section{Citation/Publisher Attribution}

De Groot, A. S. (2013). Do Tregitopes have the potential to impact the current treatment landscape of autoimmune diseases? Expert Review of Clinical Immunology, 9(12), 1155-1157.

Available at: http://dx.doi.org/10.1586/1744666X.2013.858602

This Article is brought to you for free and open access by the Institute for Immunology and Informatics (iCubed) at DigitalCommons@URI. It has been accepted for inclusion in Institute for Immunology and Informatics Faculty Publications by an authorized administrator of DigitalCommons@URI. For more information, please contact digitalcommons-group@uri.edu. 


\title{
Do Tregitopes have the potential to impact the current treatment landscape of autoimmune diseases?
}

\author{
Anne S. De Groot ${ }^{1,2}$ \\ ${ }^{1}$ EpiVax, Inc., 146 Clifford Street, Providence, RI 02903, USA and ${ }^{2}$ Institute for Immunology and Informatics, 80 \\ Washington Street, Providence, RI 02903, USA
}

\begin{abstract}
Current treatment of autoimmune disease usually involves the use of cytotoxic drugs or biologic agents that interfere with the activity of B cells, T cells or key cytokines, such as TNF, IL-1 and IL-6. On occasion, polyclonal immunoglobulin G (IgG), intravenous (IVIg) is used. The discovery of IgG- (and hence IVIg-) derived T regulatory (Treg) epitopes that trigger the expansion of Tregs in vitro and in vivo provides a novel explanation for the effect of IVIg. These IgG-derived Treg epitopes (also known as Tregitopes) appear to be effective on their own (in vivo, in autoimmune disease models) and when co-administered with a specific autoimmune disease antigen, contribute to antigen-specific tolerance induction. A description of Tregitopes and a brief discussion of their potential applications in autoimmune disease are provided here. Tregitope-based immunotherapy has the potential to modify the current autoimmune pharmacopeia.
\end{abstract}

Tregitopes are regulatory T-cell epitope sequences contained in $\lg$ that were discovered by the team of De Groot and Martin in the course of searching for T effector (Teff) epitopes in monoclonal antibody (mAb) therapeutics [1,2]. These highly conserved (in $\lg G$ ), promiscuous Treg epitopes have been shown to trigger the expansion of Tregs in vitro. A retrospective review of the T-cell epitope (and Tregitope) content of therapeutic mAbs, published in 2009 [3], revealed a close correlation between the presence of Tregitopes and the absence of HLAbinding Teff epitopes, with the lack of mAb immunogenicity in clinical use.

Taking this observation one step further, the presence of Treg epitopes in IgG might explain why immunoglobulins, which are produced by $\mathrm{B}$ cells that undergo somatic hypermutation in the periphery, do not generally elicit the expected immune response against the new 'foreign' hypervariable (complementarity determining regions, or CDR) sequences. Recognition of the importance of Tregitopes in mAb therapeutics led to the incorporation of Tregitope specific adjustments in certain immunogenicity predictions, improving the accuracy of the results $[4,5]$.

Tregitopes may also explain, in part, the tolerance-inducing effect of intravenous immunoglobulin (IVIg) therapy [6]. This theory is supported by reports that IVIg-induced expansion of Tregs in vitro and in vivo, [7-9], and IVIg experts generally agree that Treg epitopes such as Tregitopes may be contributing to the tolerizing effects of IVIg [10,11]. Although it is only approved for use in a handful of diseases [12], IVIg is used off-label for hundreds of conditions [13-19].

Recently published in vivo studies of Tregitopes in mouse models of human autoimmune diseases have further validated the Tregitope discovery [20]. Additional publications demonstrate that co-administration of Tregitopes with target antigens in vivo and in vitro leads to the induction of antigen-specific tolerance [2,21] and suppression of both humoral [22] and cellular immune responses, including antigen-specific CD8+ T-cell response [6,23]. 'Control' peptides have been compared in vitro and in vivo [24] and have not been shown to have the same effect. In another recent publication, cross-conservation (at the T-cell receptor surface) with other highly conserved T-cell epitopes in autologous proteins is identified as a potential distinguishing feature of Treg epitopes (such as Tregitopes) but not from Teff epitopes [25]. 
Other groups have reported that specific IgG-derived peptides subsequently identified as Tregitopes [26-28] induce tolerance in animal and human autoimmune disease, providing independent confirmation of Tregitope studies.

The proposed Tregitope mechanism of action is distinct from some IVIg mechanisms of action but similar to others (FIGURE 1). For example, Tregitopes are unlikely to be involved in the induction of tolerance by the formation of immune complexes, blockade of Fc receptors and thereby clearance of anti-self-antibodies; immuno-modulation via antiidiotypic interactions, inhibition of complement-mediated tissue damage and inhibition of superantigen-mediated T-cell activation; but may be involved in tolerance induction following interaction of sialylated Fc with DC-SIGN, and in direct modulation of cytokine expression (by Tregs); as well as induction of Tregs [13]. IVIg has also recently been shown to be associated with modulation of the regulatory T-cell axis, reduction of IL-17 and enhancement of the suppressive function of Tregs. Many of these effects can be explained by uptake of Tregitope by antigen-presenting cells, processing and presentation of Tregitopes to $T$ cells, which respond by inducing Tregs to be activated and express FoxP3 and CD25. IgG processing and epitope presentation is likely to occur when the $\operatorname{lgG}$ recycling protein, FcRN, is overwhelmed (as it may be when high doses of $\lg \mathrm{G}$, as in IVIg, are given).

The discovery of Tregitopes naturally led to the concept of actively integrating Tregitopes into biologics. Tolerization of immune responses to protein therapeutics (by introduction of Tregitopes) could be considered to be an alternative to humanization of mAbs, and it might also be applied to non-mAb biologic products [20]. Tolerization across the breadth of HLA alleles expressed in the general human population would involve inclusion of the complete repertoire of Tregitopes present in each IgG that is developed for clinical applications. Studies that support the effectiveness of this approach have been carried out by De Groot and Cousens et al. $[6,20,21]$ and are currently underway in the laboratories of a number of other research groups $[22,23]$.

The origin of Tregitope-specific T cells is as yet undetermined. They may be natural Tregs, induced Tregs or both. Regardless of the origin or mechanism of action of Tregitopes, the potential for these peptides to alter the course of autoimmune diseases as a replacement for cytotoxic therapy, or as an alternative to biological disease modifiers, is certainly worth consideration. Albumin has been proposed as a carrier for Tregitopes, since albumin itself may contain Tregitopes, and it has been used with a wide range of therapeutic proteins as a stable and non-immunogenic excipient.

Tregitopes may also be useful for their IVIg-like effects in conditions such as allergy, where Treg induction is considered to be important but IVIg was considered to be too dangerous (and expensive) to use as therapy. Tregitopes could be combined with the target of autoimmunity, where the target is known, such as glutamic acid decarboxylase (GAD 65) protein in diabetes. For example, early studies in autoimmune disease models clearly demonstrate that Tregitopes have promise as a standalone treatment for autoimmune disease $[6,20]$. Where the antigen is unknown, Tregitope immunotherapy might be given during a flare, when autoimmune antigens are being presented to the immune system by activated antigenpresenting cells. Whether used on their own, or co administered with a specific autoimmune disease antigen, Tregitope-based immunotherapy has the potential to augment future therapeutic options for autoimmune disease.

\section{Acknowledgements}

The assistance of R Martin, K Confreda and LP Cousens with the preparation of the manuscript and figures is sincerely appreciated. Artwork was designed and contributed by GS De Groot. The author also thanks DW Scott for a critical reading of the manuscript prior to submission. 


\section{Financial \& competing interests disclosure}

The author is founder and majority owner of EpiVax, Inc., a biotechnology company that provides immunogenicity screening services and access to the Tregitope technology on a feefor-service basis. Due to this relationship with EpiVax, the author acknowledges that there is a potential conflict of interest inherent in the publication of this manuscript, and asserts that she made an effort to reduce or eliminate that conflict where possible. The author has no other relevant affiliations or financial involvement with any organization or entity with a financial interest in or financial conflict with the subject matter or materials discussed in the manuscript apart from those disclosed.

\section{References}

1 De Groot AS, Scott DW. Immunogenicity of protein therapeutics. Trends Immunol. 28(11), 482-490 (2007).

2 De Groot AS, Moise L, McMurry JA et al. Activation of natural regulatory T cells by IgG Fcderived peptide "Tregitopes." Blood 112(8), 3303-3311 (2008).

3 De Groot AS, Martin W. Reducing risk, improving outcomes: bioengineering less immunogenic protein therapeutics. Clin. Immunol. 131(2), 189-201 (2009).

4 Cousens LP, Jawa V, Awwad M, Wakshull E, Kropshofer H, De Groot AS. T-cell dependent immunogenicity of protein therapeutics: preclinical assessment and mitigation. Clin. Immunol. (2013) (In Press).

5 De Groot AS, Terry F, Cousens LP, Martin W. Beyond Humanization and Deimmunization: tolerization as a method for reducing the immunogenicity of biologics. Exp. Rev. Clin.

Pharmacol. (2013) (In Press).

6 Cousens LP, Tassone R, Mazer BD, Ramachandiran V, Scott DW, De Groot AS. Tregitope update: mechanism of action parallels IVIg. Autoimmun. Rev. 12(3), 436-443 (2012).

7 Schuster SJ, Neelapu SS, Gause BL et al. Vaccination with patient-specific tumorderived antigen in first remission improves disease-free survival in follicular lymphoma. J. Clin. Oncol. 29(20), 2787-2794 (2011).

8 Ephrem A, Chamat S, Miquel C et al. Expansion of CD4+CD25+ regulatory T cells by intravenous immunoglobulin: a critical factor in controlling experimental autoimmune encephalomyelitis. Blood 111(2), 715-722 (2008).

9 Tsurikisawa N, Saito H, Oshikata C, Tsuburai T, Akiyama K. High-dose intravenous immunoglobulin treatment increases regulatory $\mathrm{T}$ cells in patients with eosinophilic granulomatosis with polyangiitis. J. Rheumatol. 39(5), 1019-1025 (2012).

10 Schwab I, Nimmerjahn F Intravenous immunoglobulin therapy: how does IgG modulate the immune system? Nat. Rev. Immunol. 13(3), 176-189 (2013).

11 Soukhareva N, Jiang Y, Scott DW. Treatment of diabetes in NOD mice by gene transfer of Ig-fusion proteins into B cells: role of T regulatory cells. Cell Immunol. 240, 41-46 (2006).

12 Shoenfeld Y, Katz U. IVIg therapy in autoimmunity and related disorders: our experience with a large cohort of patients. Autoimmunity 38(2):123-137 (2005). 
13 Jordan SC, Toyoda, M, Vo AA. Regulation of immunity and inflammation by intravenous immunoglobulin: relevance to solid organ transplantation. Expert Rev. Clin. Immunol. 7(3), 341348 (2011).

14 Zandman-Goddard G, Krauthammer A, Levy Y, Langevitz P, Shoenfeld Y. Long-Term Therapy with Intravenous Immunoglobulin is Beneficial in Patients with Autoimmune Diseases. Clin. Rev. Allergy Immunol. 42(2), 247-255 (2012).

15 Zandman-Goddard G, Blank M, Shoenfeld Y. Intravenous immunoglobulins in systemic lupus erythematosus: from the bench to the bedside. Lupus 18(10), 884-888 (2009).

16 Dykes AC, Walker ID, Lowe GD, Tait RC. Combined prednisolone and intravenous immunoglobulin treatment for acquired factor VIII inhibitors: a 2-year review. Haemophilia 7(2), 160-163 (2001).

17 Cines DB, Liebman H, Stasi R. Pathobiology of secondary immune thrombocytopenia. Semin. Hematol. 46(1 Suppl. 2), S2-S14 (2009).

18 Lozeron $\mathrm{P}$, Adams D. Advances in the treatment of chronic inflammatory demyelinating neuropathies in 2010. J. Neurol. 258(9), 1737-1741 (2011). 19 Rajabally YA, Mahdi-Rogers M. Overview of the pathogenesis and treatment of chronic inflammatory demyelinating polyneuropathy with intravenous immunoglobulins. Biologics 4, 45-49 (2010).

20 Cousens LP, Najafian N, Mingozzi F et al. In vitro and in vivo studies of IgG-derived Treg epitopes (Tregitopes): A promising new tool for tolerance induction and treatment of autoimmunity. J. Clin. Immunol. 33(1), 43-49 (2013).

21 Cousens LP, Su Y, McClaine E et al. Application of IgG-derived natural Treg epitopes (IgG Tregitopes) to antigen-specific tolerance induction in a murine model of type 1 diabetes. J. Diabetes Res. 2013, 621693 (2013).

22 Su Y, Rossi R, De Groot AS, Scott DW. Regulatory T cell epitopes (Tregitopes) in IgG induce tolerance in vivo and lack immunogenicityper se. J. Leukoc. Biol. 94(2), 377-383 (2013).

23 Hui DJ, Basner-Tschakarjan E, Chen $Y$ et al. Modulation of CD8+ T cell responses to AAV vectors with IgG-derived MHC class II epitopes. Mol Ther. 21(9), 1727-1737 (2013).

24 Cousens LP, Mingozzi F, van der Marel S et al. Teaching tolerance: New approaches to enzyme replacement therapy for Pompe disease. Hum. Vaccin. Immunother. 8(10), 1459-1464 (2012).

25 Moise L, Gutierrez AH, Bailey-Kellogg C et al. The two-faced T cell epitope: Examining the host-microbe interface with JanusMatrix. Hum. Vaccin. Immunother. 9(7), 1577-1586 (2013).

26 Hahn BH, Singh RP, La Cava A, Ebling FM. Tolerogenic treatment of lupus mice with consensus peptide induces Foxp3-expressing, apoptosis-resistant, TGFbeta-secreting CD8+ T cell suppressors. J. Immunol. 175(11), 7728-7737 (2005). 
27 Sharabi A, Zinger H, Zborowsky M, Sthoeger ZM, Mozes E. A peptide based on the complementarity-determining region 1 of an autoantibody ameliorates lupus by up-regulating CD4+CD25+ cells and TGF-beta. Proc. Natl Acad. Sci. USA 103(23), 8810-8815 (2006).

28 Sharabi A, Dayan M, Zinger H, Mozes E. A new model of induced experimental systemic lupus erythematosus (SLE) in pigs and its amelioration by treatment with a tolerogenic peptide. J. Clin. Immunol. 30(1), 34-44 (2010). 